\title{
Rapid and Green Method Forensic Authentication of Rice Using Near-Infrared Spectroscopy (NIRS)
}

\author{
Francisco S. Panero ${ }^{1,4}$, Pedro S. Panero ${ }^{2}$, João S. Panero ${ }^{2}$, Fernando S. E. D. V. Faria' ${ }^{3,4}$ \\ \& Anselmo F. R. Rodriguez ${ }^{3,4}$ \\ ${ }^{1}$ Chemistry Department, Federal University of Roraima, Boa Vista, Brazil \\ ${ }^{2}$ Federal Institute of Science and Technology of Roraima, Boa Vista, Brazil \\ ${ }^{3}$ Science and Technology Innovation Program, Federal University of Acre, Rio Branco, Brazil \\ ${ }^{4}$ Biodiversity and Biotechnology Network of the Legal Amazon, Biotechnology Department, Federal University \\ of Acre, Rio Branco, Brazil \\ Correspondence: Anselmo F. R. Rodriguez, Biodiversity and Biotechnology Network of the Legal Amazon, \\ Biotechnology Department, Federal University of Acre, Road BR 364, Km 04, CEP 69915-900, Rio Branco, \\ Brazil. Tel: 55-683-901-2719. E-mail: ruiz@ufac.br
}

Received: April 26, 2020

doi:10.5539/jas.v12n7p105
Accepted: June 1, $2020 \quad$ Online Published: June 15, 2020

URL: https://doi.org/10.5539/jas.v12n7p105

\begin{abstract}
Rice is one of the most consumed cereals in the world. Currently, techniques for the authentication and geographical origin of rice is known not to be objective because to depend on the naked eye of a well-trained inspector. DNA fingerprint methods have been shown to be inappropriate for on-site application because the method needs a lot of labor and skilled expertise. Rice consumers want to confirm cultivation origin because they believe price or eating score has a high correlation according to them. Considering rice as a raw material of economic and social value and the recent use of NIR spectroscopy coupled with chemometric methods to authentication and discrimination of geographical origin as an alternative to classical methods in the search for a methodology in line with Green Chemistry, this work investigates the potential of NIR spectroscopy combined with multivariate analysis: PCA (Principal Component Analysis) and HCA (Hierarchical Cluster Analysis) for rapid and non-destructive forensic authentication of rice grains from Brazil and Venezuela. This study investigated the potential of near-infrared spectroscopy, combined with PCA and HCA chemometric technique to the authenticity of rice. It was verified that is feasible and advantageous to implement authenticity detection of different brands, typology and geographical discrimination (Brazil and Venezuela) rice.
\end{abstract}

Keywords: chemometrics methods, food classification, geographical discrimination, multivariate data analysis, non-destructive identification

\section{Introduction}

Nowadays, scientists are seeking to develop methodologies that do not harm the environment. In the literature, some researchers have proposed the new concept of "Green Chemistry", which is sometimes called "Clean Chemistry" or "Environmentally Benign Chemistry" (He, Tang, Wu, Hou, \& Lee, 2007). Green Chemistry refers to the use of a set of principles that prioritize the reduction or elimination of the use or generation of hazardous substances in the design, manufacture, and application of chemicals (Anastas \& Warner, 1998).

Anastas and Warner (1998) proposed 12 complementary principles to maximize resource efficiency and minimize environmental and human health risks. The principles are as follows (American Chemical Society, 2018): (1) Prevention. (2) Atom Economy. (3) Less Hazardous Chemical Syntheses. (4) Designing Safer Chemicals. (5) Safer Solvents and Auxiliaries. (6) Design for Energy Efficiency. (7) Use of Renewable Feedstocks. (8) Reduction of Derivatives. (9) Catalysis. (10) Design for Degradation. (11) Real-time Analysis for Pollution Prevention. (12) Inherently Safer Chemistry for Accident Prevention.

The most important of the twelve principles is the first (because avoiding waste is better than treating or cleaning the waste generated) (He et al., 2007). Many conventional analytical methods are not green, as they produce harmful residues during and after analytical processes. However, the key priorities (Namieśnik, 2001) can reduce or eliminate reagent consumption and minimize the working time through highly efficient analyses. The 
analytical methods used in green chemistry are an important trend in analytical chemistry because of sustainable development that is useful for society.

Authenticity is an important issue for the food industries due to legal compliance, economic reasons and guarantee of quality. But the majority of analytical methods and techniques used for authentication and discrimination of geographical origin of food products are destructive, slow and generate waste to the environment (Gliszczyńska-Świgło \& Chmielewski, 2017).

\subsection{Near Infrared Spectroscopy}

The near-infrared spectroscopy (NIR) covers the region of the electromagnetic spectrum from 780-2500 nm and is dominated mainly by overtones and combinations of $\mathrm{O}-\mathrm{H}, \mathrm{N}-\mathrm{H}, \mathrm{C}-\mathrm{H}$ vibrations in addition to others $\mathrm{C}-\mathrm{O}$, $\mathrm{C}=\mathrm{O}, \mathrm{S}-\mathrm{H}, \mathrm{C}-\mathrm{C}, \mathrm{C}-\mathrm{Cl}$ (Panero et al., 2017).

NIR spectroscopy is increasingly used in the food industry and agriculture. Attributes such as ease of sample handling, speed, nondestructive analysis, the possibility of routine, in-line, in-situ and the combination with chemometric methods aiming at qualitative and quantitative analyses have made NIR analysis more versatile by increasing its use (Burns \& Ciurczak, 2007; Ozaki, McClure, \& Christy, 2007; Roggo et al., 2007; Sablinskas, Steiner, \& Hof, 2003; Sun, 2009).

Because of the above, there is a need for fast, non-destructive, noninvasive and low-cost analytical methodologies for authentication and geographical discrimination origin. Among these methodologies, the near-infrared spectroscopy (NIR) is highlighted. NIR spectroscopy has been used as an alternative because is considered a powerful tool for quantitative and qualitative analysis of chemical and physical variables.

This information of NIR spectrum not easily perceptible without the help of computation, mathematical treatments and statistical methods to identify redundant, relevant and anomalous information, besides correcting scattering of signals, noise, identifying patterns, among others.

\subsection{Rice}

Rice (Oryza sativa) is considered the main source of energy for the majority of humanity, being characterized as the main food for more than half of the world population. Brazil is the largest producer of rice in Latin America and the tenth-largest producer in the world (Food and Agriculture Organization, 2008). According to data from IBGE (Instituto Brasileiro de Geografia e Estatística, 2009), cereal contributes about $20 \%$ of the daily caloric intake of Brazilians. In Brazil, consumption per capita is $108 \mathrm{~g}$ per day (Walter, Marchezan, \& Avila, 2008). Consumer preference for this cereal is associated with economic, traditional, and cultural aspects, varying from country to country and even from region to region within the same country (Pereira, 2002).

The authentication and geographical origin of rice are performed by several methods and techniques fluorescence-based ISSR-PCR and SSR markers, DNA fingerprinting, inductively coupled plasma mass spectrometry (Choudhury, Kohli, Srinivasan, Mohapatra, \& Sharma, 2001; Nagaraju, Kathirvel, Kumar, Siddiq, $\&$ Hasnain, 2002), however, these methods are destructive.

Considering rice as a raw material of economic and social value and the recent use of NIR spectroscopy coupled with chemometric methods to authentication and discrimination of geographical origin as an alternative to classical methods in the search for a methodology in line with Green Chemistry, this work investigates the potential of NIR spectroscopy combined with multivariate analysis: PCA (Principal Component Analysis) and HCA (Hierarchical Cluster Analysis) for rapid and non-destructive forensic authentication of rice grains from Brazil and Venezuela.

\section{Method}

\subsection{Samples and Studied Area}

The state of Roraima is located in northern Brazil, in the region of the Western Amazon, it borders the nations of Bolivarian Republic of Venezuela (North and West) and Cooperative Republic of Guyana (East and North), with latitude: $1^{\circ} 20^{\prime} 05.1^{\prime \prime} \mathrm{N}$ and longitude: $61^{\circ} 18^{\prime} 11.6^{\prime \prime}$ with surface area of about $225,000 \mathrm{~km}^{2}$. The border of Brazil with Venezuela has an extension of 2,199.0 km, of which $954 \mathrm{~km}$ with Roraima. With these numbers, the reality of border control and surveillance becomes a huge challenge. Pacaraima city, located in Roraima, has the only official border post with Venezuela. According to the Federal Police (2020), between 2017 and 2019 were registered the entry of 545,753 Venezuelans in Brazil. Hundreds of people are clandestinely crossing Venezuela's border with Brazil on foot. The illegal route between Brazil and Venezuela is called the 'greenway' because it is inside the woods. There is a border trail, about two or three kilometers long, that people can enter Pacaraima without going through the police checkpoint (Marchao, 2019). 
The clandestine crossing between the two countries lasts between 10 and 20 minutes (Brandão \& Costa, 2019). At the border, there is a daily movement from one side to the other, which has result in a significant increase in the migration of Venezuelans to Roraima (Brazil) due to the political crisis experienced in Venezuela, with which there was an increase in smuggling and misuse of fuel, food products, cosmetics, pharmaceutical products, weapons, electronics etc. Besides, the neighboring country has products with attractive prices due to the attractive parallel exchange rate in the border.

In Roraima, different types of rice are marketed at different prices, but unfortunately, the product, when bagged, is not subject to rigorous supervision and this opens the possibility of fraudulent marketing, causing harm to the consumer.

For this study, two commercial rice (Faccio and Prato Chic), produced in the State of Roraima (Brazil), acquired in the local commerce and one commercial rice (Cristal) originating in Venezuela, obtained in the informal free fairs where products from the neighboring country (Venezuela) are found.

\subsection{Acquisition of Spectral and Chemometrics Data Treatment}

Diffuse reflectance spectra in the near-infrared region of the rice grain samples were obtained in the PerkinElmer brand "Spectrum Two FT-IR" spectrophotometer, in the spectral range of 700 to $2400 \mathrm{~nm}$. For the acquisition of the spectra, the raw rice samples (without pretreatment) were placed in glass flasks of $30 \mathrm{~mL}$ with transparent and uniform walls. Thirty spectral samples were acquired from each commercial rice of Brazil, and fifteen spectral samples were acquired from commercial rice of Venezuela. Each spectrum was acquired with a resolution of $4 \mathrm{~cm}^{-1}$, with a mean spectrum of 50 scans in $30 \mathrm{~s}$. Totalizing 75 samples $($ Faccio $=30$; Prato Chic $=$ 30 and Cristal $=15$ ), which resulted in a matrix of $75 \times 4859$.

One of the most important multivariate methods of data analysis is PCA (Principal Component Analysis), based on the correlation among variables. PCA is a non-supervised technique, that reduces the dimensionality of the original data

Matrix and enables the description of the information present in the original data by visual interpretation of the possible relationships between the samples (Ferreira, 2015; Souza \& Poppi, 2012). This method (PCA), with mean-center preprocessing, was used in the analysis of matrix data.

HCA (Hierarchical Cluster Analysis) is another important non-supervised multivariate method of data analysis. The HCA method, with mean-center preprocessing, Euclidean distance and incremental linkage method, was also used to confirm the similarity of samples by grouping, this method, like the previous one, works through of the recognition of unsupervised patterns, but allow two-dimensional graphical representations by the dendrogram. The results presented in the form of dendrograms, make it possible to visualize the relationships between samples, the distances between samples or variables are calculated and compared through the similarity scale which ranges from zero (none similarity and a large distance between the samples) to one.

\section{Results and Discussion}

\subsection{NIR spectra}

The raw near-NIR infrared spectra of 3 different brands of polished white rice grains, type 1, in the range 700 to $2400 \mathrm{~nm}$, are shown in Figure 1. 


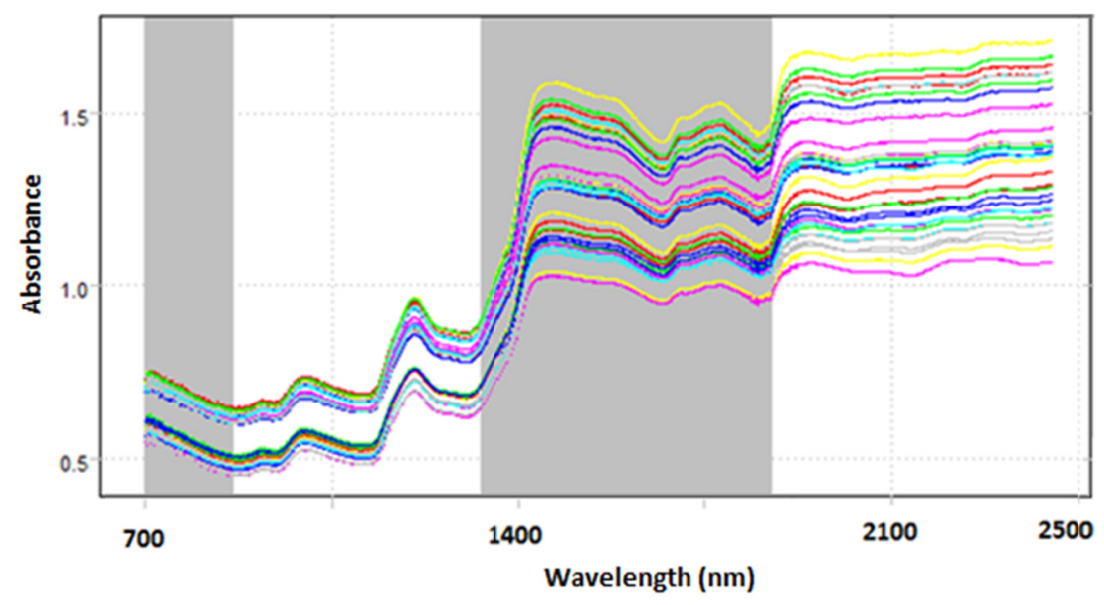

Figure 1. Raw spectra of rice seeds $(700-2400 \mathrm{~nm})$

Figure 1 it is possible to verify the difficulty in identifying the spectrum that corresponds to each type of rice without the use of statistical and computational resources.

Due to the inhomogeneity in rice grain size and distribution, diffuse reflectance spectra in the near-infrared region are scattered and offset compared to the baseline. In order to reduce this instrumental spreading, several smoothing and noise reduction techniques were applied.

After several tests with spectral ranges and mathematical methods of signal preprocessing, it was noted that the best result was obtained by centering the data on the average associated with the application of MSC (Multiplicative Scatter Correction) + first derivative, in the spectral range from $867 \mathrm{~nm}$ to $1327 \mathrm{~nm}$ and $1876 \mathrm{~nm}$ at $2400 \mathrm{~nm}$.

\subsection{Statistics and Data Analysis}

With the application of the Hierarchical Cluster Analysis (HCA) technique to the NIR spectral data in intact rice grains, it was possible to observe the formation of 3 large groups in the resulting dendrogram, as shown in Figure 2. The sample group of polished white rice, type agulinha (FACCIO), in yellow; another large group of polished white rice, type agulinha, in red (PRATO CHIC); and in green, the group of polished white rice (CRISTAL) from Venezuela.

It can be observed that the incremental connection method used above for dendrogram production allows the authentication of rice grains from different brands (FACCIO and PRATO CHIC), even though they are white rice, polished and of the same variety. In addition, it can be seen from Figure 2 that the marks unite with $40 \%$ similarity, forming another large group, which we can identify as rice produced in the state of Roraima (Brazil). Therefore, the model can also group the rice samples from the neighboring country (Venezuela), showing that it has almost zero similarity with the samples produced in Brazil. In this context, we can verify that the method used would be an excellent alternative for forensic analysis, capable of identifying smuggled food products. 


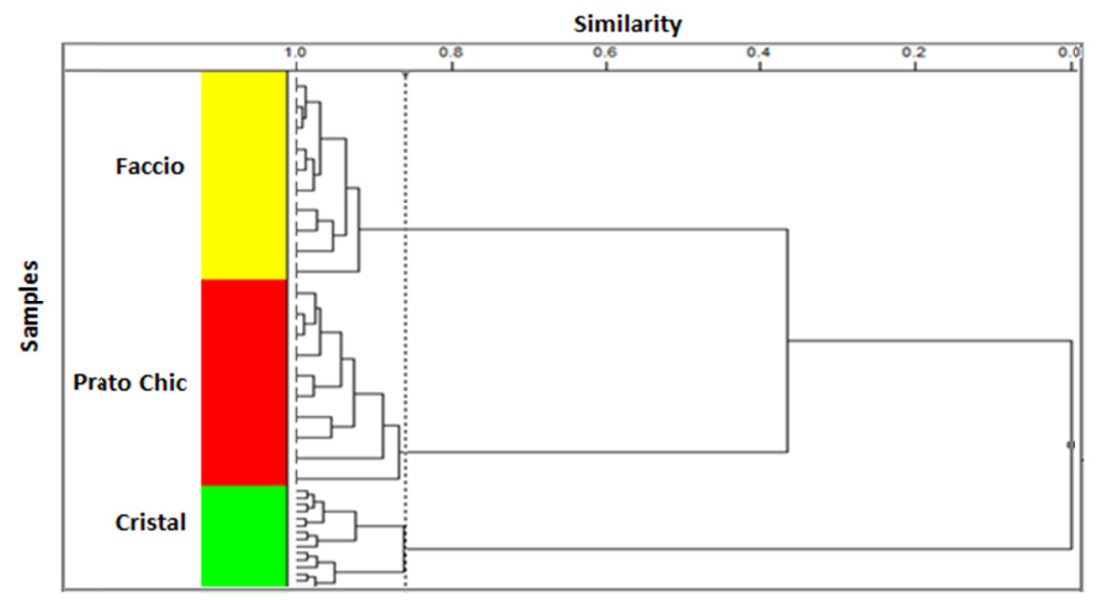

Figure 2. Discrimination of three brands of white rice, using NIR spectra after centering on the average and application of MSC +1 st derivative, by the HCA technique using the incremental connection

For the forensic identification and authentication of the different rice brands produced in the state of Roraima and those from Venezuela, the Principal Component Analysis (PCA) technique was also applied as an unsupervised pattern recognition method in the NIR spectra in the spectral range from $867 \mathrm{~nm}$ to $1327 \mathrm{~nm}$ and $1876 \mathrm{~nm}$ to $2400 \mathrm{~nm}$, the mathematical model that obtained the best discrimination between the studied brands was obtained by centering the data on the average, associated with the application of MSC (Multiplicative Scatter Correction) + first derivative and the use of 2 principal components, which made it possible to explain $98.66 \%$ of the total variance, with PC1 accounting for $95.42 \%$; and PC2 3.24\%, according to the score graph observed in Figure 3, in which we can observe the well-defined discrimination of three large groups: the group of samples of polished white rice, type agulinha (FACCIO), in yellow; another group of polished white rice, type agulinha, in red (PRATO CHIC); and in green, the group of polished white rice (CRISTAL), from Venezuela, in accordance with the result obtained by the HCA.

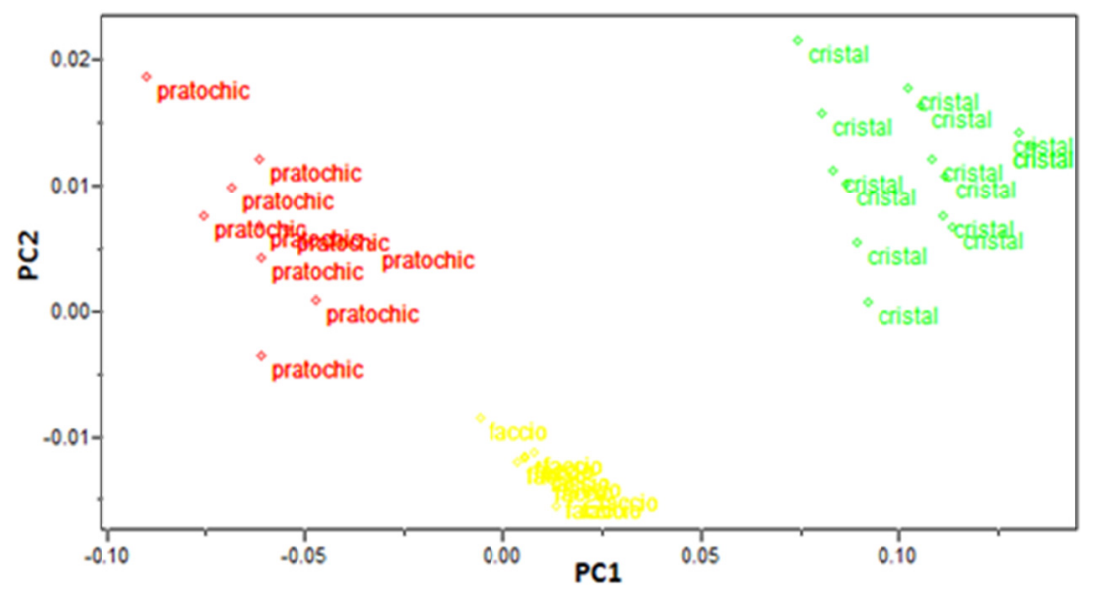

Figure 3. Separation of three different brands of white rice, using NIR spectra after centering on the average and application of MSC +1 st derivative, by the PCA technique

\section{Discussion}

This study investigated the potential of near-infrared spectroscopy, combined with PCA and HCA chemometric technique to the authenticity of rice and found is feasible and advantageous to implement authenticity detection of different brands, typology and geographical discrimination (Brazil and Venezuela) of rice. Therefore, it can serve as an alternative to laborious, time-consuming, wet chemical methods and of sensory analysis of humans. 


\section{Acknowledgments}

We would like to thank the Doctoral Program of the Biodiversity and Biotechnology Network of the Legal Amazon of the Federal University of Acre (UFAC) and Federal University of Roraima (UFRR) for giving permission to use the laboratory and equipment that fundamentally contributed to the work's feasibility.

\section{References}

American Chemical Society. (2019). 12 principles of green chemistry. Retrieved from https:/www.acs.org/ content/acs/en/greenchemistry/what-is-green-chemistry/principles/12-principles-of-green-chemistry.html

Anastas, P. T., \& Warner, J. C. (1998). Green Chemistry: Theory and practice. New York, NY: Oxford University Press.

Brandão, I., \& Costa, E. (2019, November 10). Centenas de pessoas cruzam a pé fronteira da Venezuela com Roraima. Retrieved from https://g1.globo.com/rr/roraima/noticia/2016/12/centenas-de-pessoas-cruzam-pefronteira-da-venezuela-com-roraima.html

Burns, D. A., \& Ciurczak, E. W. (2007). Handbook of near-infrared analysis (3nd ed.). Boca Raton, FL: CRC Press. https://doi.org/10.1201/9781420007374

Choudhury, P. R., Kohli, S., Srinivasan, K., Mohapatra, T., \& Sharma, R. P. (2001). Identification and classification of aromatic rices based on DNA fingerprinting. Euphytica, 118(3), 243-251. https://doi.org/ 10.1023/A:1017554600145

Federal Police. (2020). Imigração Venezuela/Brasil-Polícia Federal. Retrieved from http://www.pf.gov.br/ servicos-pf/imigracao/Apresentao_Novembro_2019_VFinal_RETIFICADA

Ferreira, M. M. C. (2015). Quimiometria-Conceitos, métodos e aplicações. Campinas, SP: UNICAMP. https://doi.org/10.7476/9788526814714

Food and Agriculture Organization. (2020). Statistical databases agriculture. Retrieved from http://apps.fao.org/ page/collections? subset $1 / 4$ agriculture

Gliszczyńska-Świgło, A., \& Chmielewski, J. (2017). Electronic nose as a tool for monitoring the authenticity of food. Food Analytical Methods, 10, 1800-1816. https://doi.org/10.1007/s12161-016-0739-4

He, Y., Tang, L., Wu, X., Hou, X., \& Lee, Y. (2007). Spectroscopy: The best way toward green analytical chemistry? Applied Spectroscopy Reviews, 42(2), 119-138. https://doi.org/10.1080/05704920601184259

Instituto Brasileiro de Geografia e Estatística. (2020). Levantamento sistemático da produção agrícola: Março 2009. Grupo de Coordenação de Estatísticas Agropecuárias-GCEA/IBGE, DPE, COAGRO. Retrieved from http://www.ibge.gov.br/home/estatistica/indicadores/agropecuaria/lspa/ lspa_200903_7.shtm

Marchao, T. (2019, October 16). Transporte caro ou dias a pé: Como é a travessia dos venezuelanos para viver no Brasil. Retrieved from https:/noticias.uol.com.br/internacional/ultimas-noticias/2018/02/26/fronteiravenezuela-pacaraima.htm

Nagaraju, J., Kathirvel, M., Kumar, R. R., Siddiq, E. A., \& Hasnain, S. E. (2002). Genetic analysis of traditional and evolved Basmati and non-Basmati rice varieties by using fluorescence-based ISSR-PCR and SSR markers. Proceedings of the National Academy of Sciences, 99(9), 5836-5841. https://doi.org/10.1073/ pnas.042099099

Namieśnik, J. (2001). Green analytical chemistry-Some remarks. Journal of Separation Science, 24, $151-153$. https://doi.org/10.1002/1615-9314(20010201)24:2<151::AID-JSSC151>3.0.CO;2-4

Ozaki, Y., McClure, W. F., \& Christy, A. A. (2007). Near-infrared spectroscopy in food science and technology. Hoboken, NJ: John Wiley \& Sons. https://doi.org/10.1002/0470047704

Panero, J. S., Silva, H. E. B., Panero, P. S., Smiderle, O. J., Panero, F. S., Faria, F. S. E. D. V., \& Rodriguez, A. F. R. (2017). Separation of cultivars of soybeans by chemometric methods using near infrared spectroscopy. Journal of Agricultural Science, 10(4), 351-360. https://doi.org/10.5539/jas.v10n4p351

Pereira, J. A. (2002). Cultura do arroz no Brasil: Subsidios para a sua história (p. 226). Teresina, PI: Embrapa Meio-Norte.

Roggo, Y., Chalus, P., Maurer, L., Lema-Martinez, C., Edmond, A., \& Jent, N. (2007). A review of near infrared spectroscopy and chemometrics in pharmaceutical technologies. Journal of Pharmaceutical and Biomedical Analysis, 44(3), 683-700. https://doi.org/10.1016/j.jpba.2007.03.023 
Sablinskas, V., Steiner, G., \& Hof, M. (2003). Aplications. In G. Gauglitz \& T. Vo-Dinh (Eds.), Handbook of spectroscopy (pp. 89-168). Weinheim, Germany: Wiley-VCH. https://doi.org/10.1002/3527602305.ch6

Souza, A. M., \& Poppi, R. J. (2012). Experimento didático de quimiometria para análise exploratória de óleos vegetais comestíveis por espectroscopia no infravermelho médio e análise de componentes principais: um tutorial, parte I. Química Nova, 35(1), 223-229. https://doi.org/10.1590/S0100-40422012000100039

Sun, D. W. (2009). Infrared spectroscopy for food quality analysis and control. San Diego, CA: Elsevier Academic Press.

Walter, M., Marchezan, E., \& Avila, L. A. (2008). Arroz: Composição e características nutricionais. Ciência Rural, 38(4), 1184-1192. https://doi.org/10.1590/S0103-84782008000400049

\section{Copyrights}

Copyright for this article is retained by the author(s), with first publication rights granted to the journal.

This is an open-access article distributed under the terms and conditions of the Creative Commons Attribution license (http://creativecommons.org/licenses/by/4.0/). 